Regie Lyn P. Santos-Cortez, MD, PhD ${ }^{1,2}$ Charlotte M. Chiong, MD ${ }^{1,2}$,

Ma. Luz M. San Agustin, BSBA ${ }^{1,2}$,

Charina Melinda C. Elgar, MD",

Genilou Liv M. Gimena, MD ${ }^{3}$

Scheherazade C. Ibrahim, $\mathrm{MD}^{3}$,

Rodante A. Roldan, $\mathrm{MD}^{3}$,

Ma. Rina T. Reyes-Quintos, MD, MClinAud ${ }^{1,2}$,

Abner L. Chan, MD ${ }^{1,2}$

Generoso T. Abes, MD, MPH ${ }^{1,2}$

\section{'Philippine National Ear Institute} National Institutes of Health

University of the Philippines Manila

${ }^{2}$ Department of Otorhinolaryngology

College of Medicine - Philippine General Hospital

University of the Philippines Manila

${ }^{3}$ Department of Otorhinolaryngology

Philippine General Hospital

University of the Philippines Manila

\title{
The Philippine National Ear Institute: Patient and Audilogic Profiles
}

\begin{abstract}
Background: The Philippine National Ear Institute (PNEI) was created to promote health of hearing and balance among Filipinos. Over the years, it has provided audiologic services to thousands of patients annually and has published relevant hearing and balance research.

Objective: To describe the patients served by the PNEI in terms of age, region of origin, occupation, pretest diagnosis, and audiologic results.

\section{Methods:}

Study Design - Cross-sectional study

Setting - National tertiary care center

Population - All records of patients referred for audiologic testing at PNEI in 2006 were reviewed and encoded into analyzable format.
\end{abstract}

Results: A total of 1,756 patients had audiologic records for review. Median age was 32.5 years, with the age distribution presented according to sex, type of tests done including common reasons for referral, and median threshold levels by frequency. Coverage was national in scope, with most patients coming from the National Capital Region and from Regions III and IVa. Occupation was indicated in $37.8 \%$ of the working age group, most of whom were unemployed. The most common pretest diagnosis was chronic otitis media (26.6\%), followed by hearing loss of unknown etiology (13.0\%) and tinnitus (9.3\%). Severity of hearing impairment based on pure tone audiometry was variable, and was presented according to common diagnoses. About $39 \%$ of hearing impairment cases were sensorineural, $36 \%$ conductive and $25 \%$ due to mixed defect. Bilateral Type A ears were found in $45.4 \%$ of patients by tympanometry, while $29.3 \%$ were bilateral Type B. For otoacoustic emissions, $69.0 \%$ were labeled as "refer" in at least one ear.

Conclusion: The PNEl is a major national referral center for audiology that holds much promise in developing programs for national surveillance of the hearing status of different sectors in Philippine society.

Keywords: Philippine National Ear Institute, Philippines, patient profile, audiology, audiometry, tympanometry, otoacoustic emissions, chronic otitis media
Philippine National Ear Institute

National Institutes of Health -

University of the Philippines Manila

2nd Floor Central Block

Philippine General Hospita

Taft Avenue, Ermita, Manila 1000

Philippines

Telephone: (632) 521-8450 loc. 2153

Telefax: (632) 522-0946

Email: regie_san@earinstitute.org.ph

Reprints will not be available from the author.

No funding support was received for this study. The authors signed a disclosure that they have no proprietary or financial interest with any organization that may have a direct interest in the subject matter of this manuscript, or in any product used or cited in this article. 
ORIGINAL ARTICLES

The Philippine National Ear Institute (PNEI) was created in 2004 by Republic Act No. 9245 as a primary research institute for the promotion of health in hearing and balance among Filipinos (http://www. earinstitute.org.ph/). From an ear unit with a single audiometer and one audiometrician, the PNEI has grown to a multidisciplinary facility that performs different audiologic testing methods and promotes audiology and communication sciences through its Master of Clinical Audiology program. With the vision statement that, "No Filipino shall be deprived of a functioning sense of hearing and balance," it now serves thousands of patients annually and, through its research initiatives, has strongly advocated hearing health not only within the surrounding communities but also across the Philippine islands.

One of PNEl's main mandates is to carry out epidemiologic studies that are related to hearing and balance and that have the potential to become the basis for the government's regulatory policies. In laying the foundation for future research activities and education programs, this study aims to describe the personal and audiologic profiles of PNEI patients by collating information on age, region of origin, occupation, referral information, pretest diagnosis, and audiologic results. The composite information gathered here may be useful not only for PNEI staff but also for practicing otorhinolaryngologists, physicians, audiologists, communication scientists and government policy makers as well.

\section{METHODS}

All measurements for pure tone audiometry were performed in a soundproof booth using the Diagnostic Audiometer AD229b (Interacoustics $A / S$, Assens, Denmark). Play pure tone and visual reinforced observation audiometry (VROA) were also performed using the same equipment. Tympanometry was done with the GSI 38 tympanometer (Grason-Stadler, Inc, Milford, NH, USA) while otoacoustic emissions (OAE) were measured via Otoread (Interacoustics A/S, Assens, Denmark). Auditory brainstem response (ABR) testing was conducted with the patient under sedation or while sleeping and using the Evostar system (Pilot Blankenfelde mediz. elktr. Gerate $\mathrm{GmbH}$, Blankenfelde, Germany). Testing was performed as part of the clinical management of patients.

Information from all PNEl audiology forms for 2006 were reviewed and encoded into analyzable format. The following variables were available from the request forms: name, date of birth, age, sex, address, occupation, referring unit, date of referral, pretest diagnosis, chief complaint and otoscopic findings. These information, including pretest diagnosis, were determined and reported by consultants, residents and/or medical students upon patient consultation or referral.

For pure tone audiometry (including play pure tone audiometry), air and bone conduction levels were recorded per ear and per frequency at $250,500,1000,2000,4000$ and $8000 \mathrm{~Hz}$ whenever possible. When the measurement is indicated as beyond the limits of the audiometer, the default value was set at $120 \mathrm{~dB}$. Only the latest audiometry result was included in the analysis. To determine severity of hearing, the pure tone average at $500-2000 \mathrm{~Hz}$ was computed per ear. Severity of hearing impairment was reported as normal if the pure tone average was less than $26 \mathrm{~dB}$, mild for $26-45 \mathrm{~dB} \mathrm{HL}$, moderate for $46-60 \mathrm{~dB} \mathrm{HL}$, moderately severe 61-75 dB HL, severe 76-90 dB HL and profound for above $90 \mathrm{~dB}$ $\mathrm{HL}{ }^{1}{ }^{1}$ The type of hearing impairment was reported as sensorineural if the difference between the averages of air and bone conduction levels at $500-2000 \mathrm{~Hz}$ (air-bone gap) amount to $10 \mathrm{~dB}$ or less. On the other hand, if the air-bone gap is greater than $10 \mathrm{~dB}$, the hearing impairment was categorized as conductive. When some amount of conductive hearing loss existed while the bone conduction levels indicated sensorineural hearing loss, the hearing impairment was labeled as mixed. For VROA, hearing was categorized as normal at 0-40 dB, mild at 41-60 dB, moderate $61-80 \mathrm{~dB}$, severe $81-100 \mathrm{~dB}$ and profound if more than $100 \mathrm{~dB}$ (PNEl standard, unpublished). For OAE, a "pass" result was recorded for an ear which showed a signal-to-noise ratio of $10 \mathrm{~dB}$ with an averaged noise floor value of $-20 \mathrm{~dB}$ before the maximum number of samples collected equals 500 , and a failure or "refer" result was recorded when the $10 \mathrm{~dB}$ signal-to-noise ratio was not achieved.

Standard descriptive statistics were performed with MS Excel 2003 (Microsoft Corp., Redmond, WA, USA, 2003) and SPSS 11.0.1 software (SPSS Inc., Chicago, IL, USA, 2001).

\section{RESULTS}

A total of 1,819 patient records from all referrals for 2006 were reviewed, of which 63 were repeat tests and were therefore not included in analyses. The breakdown according to type of test follows: pure tone audiometry - 1,405; play pure tone - 105; VROA - 56; tympanometry 372; OAE - 168; ABR - 15. There were 344 individuals who had at least two tests done, thus, the total number of patient records was less than the sum of all tests performed.

\section{Patient Profile \\ General Profile}

Females comprised $50.7 \%$ of those tested. The median age was 32.5 , ranging from 0 day to 93.1 years. For the age distribution, there were two peaks: one at $0-5$ years, the other centered at about age 20 . Table 1 reports the sex distribution when the age was categorized into arbitrary groups. The pediatric age group ( $<18$ years) accounted for $27.1 \%$, about half of which were toddlers and infants (age 5 and below). Majority of the patients (59.5\%) belonged to the working age group (ages 18-60), while the remaining $13.4 \%$ were elderly.

From the patients' addresses, 1,364 were traced to different regions in the country. As expected, majority ( $n=809$ or $59.3 \%$ ) were from the National Capital Region (NCR). Of those from NCR, 232 (28.7\%) were from Manila, 99 (12.2\%) from Quezon City, and 68 (8.4\%) from Parañaque. 
Outside NCR, Region IVa had the most patients at 327 (24.0\% of total cases); from this pool of patients 148 (45.3\%) were from Cavite, while 90 (27.5\%) came from Laguna. Only $8.2 \%$ resided in Region III, but $63.4 \%$ of them $(n=71)$ lived in Bulacan. For the rest of Luzon, the number of patients per region follows: CAR - 3; I-17; II - 14; IVb - 10; V - 26. When several regions were pooled together, 26 patients were from the Visayas and 12 from Mindanao. There were no patients from the Autonomous Region of Muslim Mindanao.

Only 393 of those aged 18 and above indicated their occupation, which included $37.8 \%$ of the working age group. Classification by work category was done according to the listing by the Department of Labor and Employment. ${ }^{2}$ Of those whose jobs were known, 78 were unemployed, 41 were housewives and 21 were laborers or unskilled workers. Office workers and clerks numbered 51, while 37 were trade workers, such as factory workers, farmers and garment workers. Of the 23 professionals, 14 were teachers. Sixteen out of 22 who worked with machines or vehicles were drivers. In addition, 22 worked overseas, mostly as seafarers. The rest were variably distributed into employment for business, technical and associate professional services, sales and service work.

The referring unit was reported in 1,171 request forms. Seventyseven percent of patients were seen at the charity outpatient service, while $214(18.3 \%)$ were referred by consultants. Less than $3 \%$ were referred from other departments. The median lag time from referral to testing date was 4 days (range 0 to 302).

Based on pretest diagnosis, chief complaint and otoscopic findings, a plausible diagnosis was derived for 1,554 patients. The most common diagnosis was chronic otitis media, which totaled 414 or $26.6 \%$ of cases. Another 54 cases were reported variably as otitis media, acute otitis media, otitis media with effusion, adhesive otitis media, bullous myringitis and Eustachian tube dysfunction. Seventy-one cases were post-mastoidectomy or post-tympanoplasty. Aside from middle ear infections, hearing loss as a complaint or diagnosis with no abnormal otoscopic finding was a common cause of referral $(n=202,13.0 \%)$. Thirty-one patients had sensorineural hearing loss clinically while 62 were diagnosed with presbycusis. Tinnitus was documented in 144 cases. Common diagnoses among children included: cleft palate with or without cleft lip $(n=77)$; congenital hearing impairment $(n=31)$; speech delay $(n=44)$; and multiple congenital anomalies $(n=14)$. For balance disorders, the following were observed: benign paroxysmal positional vertigo or BPPV $(n=25)$; Meniere's disease $(n=16)$; cerebellopontine angle tumors $(n=13)$; dizziness $(n=43)$; and vertigo $(n=57)$. Hearing screening was requested for 117 cases, plus 16 that were pre- or postchemotherapy or -radiotherapy. Ototoxic hearing impairment was reported in six cases, and noise-induced hearing loss in nine patients. Twenty-five referrals were trauma-related.

\section{Profile per Test}

Pure tone audiometry (excluding play pure tone) was performed in patients with a median age of 38.7 years (range 4.3-93.1). Five days was the median lag time from referral to testing (range 0-302). Common diagnoses included chronic otitis media $(n=404)$, hearing loss $(n=184)$ and tinnitus $(n=141)$.

The median age for play pure tone audiometry patients was 5.8 years (range 2.5-16.9). Median lag time from referral to testing was 7 days (range $0-100)$. Most common reasons for referral were speech delay $(n=26)$, congenital hearing impairment $(n=13)$ and cleft palate $\pm \operatorname{lip}(n=11)$. For VROA patients, median age was 3.0 (range 0.5-8.0 years) and median referral lag time was 0 day (range 0-64). Reasons for referral were similar to play pure tone, including speech delay $(n=$ $9)$, hearing screening $(n=8)$, cleft palate $\pm \operatorname{lip}(n=7)$ and congenital hearing impairment $(n=6)$.

For tympanometry, patients with the following diagnoses had the most number: hearing loss of unknown etiology, 54; chronic otitis media, 52; cleft palate \pm lip, 44; and tinnitus, 43 . Median age was 35.7 years (range 0-88.8) while median time from referral to testing was 5 days (range 0-209).

Median age at OAE testing was 10 months (range 0-56 years), with referrals delayed for a median of 2 days (range $0-118$ ) and were usually for cleft palate $\pm \operatorname{lip}(n=48)$ and hearing screening $(n=18)$. ABR testing was done on 15 patients with a median age of 3.5 (range 8 months to 50 years). Median delay for ABR testing lasted 7 days (range 1-50 days). Note, however, that the ABR machine was out-of-service for several months. Patients were referred for ABR due to speech delay, global developmental delay, congenital hearing impairment, tinnitus, dizziness and vertigo.

\section{Audiology Results \\ Pure Tone Audiometry}

After combining formal and play pure tone audiometric results, 1,505 records were categorized according to severity based on air conduction levels per ear (Table 2). When comparing the different cells in Table 2, there seems to be a greater increase in severity of hearing impairment in the high frequencies compared to the speaking frequencies for both ears. The median threshold ( \pm standard deviation) for the right ear at the speaking frequencies $500-2000 \mathrm{~Hz}$ was $40 \mathrm{~dB}$, while at $4000-8000$ $\mathrm{Hz}$ it was $50 \mathrm{~dB}$. For the left ear, the median threshold at $500-2000 \mathrm{~Hz}$ was $43.3 \mathrm{~dB}$ and at $4000-8000 \mathrm{~Hz}$ it was $52.5 \mathrm{~dB}$. Also on a per frequency basis, based on median values, there is about a $3 \mathrm{~dB}$ threshold difference between ears. Mean speech discrimination score (SDS) for the right was $95.8 \pm 27.9 \%$ and for the left $95.7 \pm 27.9 \%$; median SDS was $100 \%$ for both ears.

To determine differences in hearing thresholds by age, median threshold levels for each age category were computed while differentiating the averages at speaking versus high frequencies for either ear (Table 3). It was shown that high-frequency loss of at least $5 \mathrm{~dB}$ compared to the speaking frequencies began at about age 30 onwards. Thresholds at the speaking frequencies also started to drop after age 45 . However, it cannot be known if this was due to presbycusis or to the natural progression of disease since this is a non-normative and heterogeneous population. For ages 12 years and less, thresholds were higher as expected due to less reliability in threshold testing at these ages.

Classification according to type of hearing impairment was possible 
ORIGINAL ARTICLES

for 1,350 records with bone conduction levels (Table 4), which excluded most of play pure tone tests. About $39 \%$ of hearing impairment cases was sensorineural, $36 \%$ conductive and $25 \%$ due to mixed defect.

Most of those who tested normal were referred for screening ( $\mathrm{n}$ $=58), 22$ of whom were medical transcriptionists and nine were to undergo chemotherapy. Forty-three patients who complained of tinnitus had normal hearing (Table 5). Mild sensorineural hearing loss was found in 13 patients diagnosed as having BPPV and in 67 with dizziness/vertigo/tinnitus, while 141 chronic otitis media patients had mild conductive hearing impairment. For moderate and moderately severe hearing impairment, the most common diagnoses were chronic otitis media and hearing loss of unknown etiology, which was similar to the general profile of patients. Compared to other categories of severity, moderately severe hearing impairment occurred more among hearing loss and presbycusis patients (Table 5). Eleven of 15 patients with congenital hearing impairment and half of patients referred for speech delay $(n=37)$ had profound loss in at least one ear. Figure 1 presents sample audiograms for common diagnoses based on median threshold levels per frequency.

\section{Visual Reinforced Observation Audiometry}

Among VROA patients ( $n=56)$, classification by severity of hearing impairment resulted in the following: normal, 7 (12.5\%); mild, 20 (35.7\%); moderate, 7 (12.5\%); severe, $8(14.3 \%)$; and profound, 14 (25.0\%). Of note, all seven cases referred for cleft palate \pm lip had only mild hearing impairment, with four having Type B ears. For the other disease conditions, severity of hearing impairment was varied.

\section{Tympanometry}

About half of patients who underwent tympanometry had normal results, followed by Type B curves in about $40 \%$ (Table 6). Most of these cases had bilateral concordance in their results, with only a quarter of patients having unilateral disease. Almost $30 \%$ had both ears as Type B. In $86.4 \%$ of cleft palate \pm lip patients $(n=44)$, at least one ear was Type B; $75 \%$ were Type B bilaterally. Remarkably only $88 \%$ of chronic otitis media cases $(n=50)$ had at least one Type $B$ ear. When hearing loss etiology was unknown $(n=54)$, bilateral Type $A$ ears were found only $44.4 \%$ of the time, that is, in more than half some middle ear pathology may have existed. Among tinnitus cases $(n=43)$, about $40 \%$ were not type A bilaterally, indicating possible middle ear disease in at least one ear in these patients.

\section{Otoacoustic Emissions}

OAE results were symmetric in about $90 \%$ of cases (Table 7). High rates of hearing impairment were seen, with $69.0 \%$ labeled as "refer" in at least one ear. Only 3 of $48(6.2 \%)$ cleft palate \pm lip cases had "pass" results for both ears. On the other hand, $55.6 \%$ of children referred for hearing screening had at least one ear as "refer". Additionally 3 of 7 preterm babies had bilateral impairment, and 1 of 7 patients for chemotherapy was affected bilaterally. Five of nine babies with suspected congenital hearing impairment were "refer" for at least one ear, while only one of 12 children with multiple congenital anomalies passed for both ears.
Table 1. Sex and age distribution of PNEl patients for 2006

$\begin{array}{lrrr}\text { Age categories (in years) } & \text { Female } & \text { Male } & \text { Total } \\ 0-1 & 31 & 73 & 104 \\ 1-5 & 65 & 76 & 141 \\ 5-12 & 59 & 64 & 123 \\ 12-18 & 54 & 52 & 106 \\ 18-30 & 169 & 168 & 337 \\ 30-45 & 187 & 183 & 370 \\ 45-60 & 184 & 150 & 334 \\ 60+ & 137 & 98 & 235 \\ \text { Total } & 886 & 864 & 1750\end{array}$

Sex was not indicated for one patient aged 25.8 years. Five females and one male did not indicate age.

Table 2. Severity of hearing impairement based on pure tone audiometry per ear

\begin{tabular}{|c|c|c|c|c|}
\hline \multicolumn{5}{|c|}{ Severity Right, $500-2000 \mathrm{~Hz}$ Right, $6000-8000 \mathrm{~Hz}$ Left, $500-2000 \mathrm{~Hz}$ Left, $6000-8000 \mathrm{~Hz}$} \\
\hline Normal & $428(28.4)$ & $401(26.6)$ & $337(22.4)$ & $350(23.3)$ \\
\hline Mild & $431(28.6)$ & $311(20.7)$ & $418(27.8)$ & $306(20.4)$ \\
\hline Moderate & $209(13.9)$ & $204(13.6)$ & $226(15.0)$ & $203(13.5)$ \\
\hline Moderately & $181(12.0)$ & $197(13.1)$ & $214(14.2)$ & $214(14.2)$ \\
\hline \multicolumn{5}{|l|}{ severe } \\
\hline Severe & $109(7.2)$ & $141(9.4)$ & $115(7.6)$ & $161(10.7)$ \\
\hline Profound & $147(9.8)$ & $251(16.7)$ & $195(13.0)$ & $269(17.9)$ \\
\hline Total & 1505 & 1505 & 1505 & 1503 \\
\hline
\end{tabular}

Table 3. Median threshold levels (in dB) per age category

\begin{tabular}{|cccccc}
\hline Age (yrs) & N & Right, $500-2000 \mathrm{~Hz}$ & Right, $6000-8000 \mathrm{~Hz}$ & Left, $500-2000 \mathrm{~Hz}$ & Left, $6000-8000 \mathrm{~Hz}$ \\
\hline$<12$ & 152 & 50 & 50 & 51.7 & 52.5 \\
$12-18$ & 105 & 35 & 37.5 & 41.7 & 40 \\
$18-30$ & 335 & 30 & 30 & 31.7 & 35 \\
$30-45$ & 358 & 33.3 & 42.5 & 35 & 45 \\
$45-60$ & 325 & 40 & 60 & 41.7 & 57.5 \\
$>60$ & 232 & 53.3 & 72.5 & 58.3 & 75 \\
\hline
\end{tabular}

Table 4. Type of hearing impairment based on pure tone audiometry per ear

$\begin{array}{lrr}\text { Type } & \text { Right } & \text { Left } \\ \text { Normal } & 322(23.9) & 234(17.4) \\ \text { Conductive } & 373(27.6) & 401(29.7) \\ \text { Sensorineural } & 410(30.4) & 432(32.0) \\ \text { Mixed } & 245(18.1) & 281(20.8) \\ \text { Total } & 1350 & 1348\end{array}$

Some patients required bone conduction level testing in only one ear. Percentages are indicated in parentheses. 
Table 5. Number of cases according to severity of hearing impairment for common diagnoses*

\begin{tabular}{lrrrrr} 
Severity & \multicolumn{1}{c}{ COM† } & \multicolumn{2}{c}{ Post-surgery } & Hearing loss ₹ Tinnitus & Presbycusis§ \\
Normal & $26(6.4)$ & $5(7.0)$ & $17(8.8)$ & $43(30.5)$ & $1(1.6)$ \\
Mild & $144(35.4)$ & $25(35.2)$ & $44(22.8)$ & $56(39.7)$ & $11(17.7)$ \\
Moderate & $97(23.8)$ & $10(18.3)$ & $36(18.7)$ & $21(14.9)$ & $11(17.7)$ \\
Moderately severe & $67(16.5)$ & $10(18.3)$ & $52(26.9)$ & $14(9.9)$ & $27(43.5)$ \\
Severe & $48(11.8)$ & $6(8.5)$ & $22(11.4)$ & $4(2.8)$ & $8(12.9)$ \\
Profound & $25(6.1)$ & $9(12.7)$ & $22(11.4)$ & $3(2.1)$ & $4(6.5)$ \\
Total & 407 & 71 & 193 & 141 & 62
\end{tabular}

* Severity was based on mean thresholds from $500-2000 \mathrm{~Hz}$ averaged between two ears. Percentages are indicated in parentheses.

†COM = chronic otitis media.

\#Eight of 17 patients who complained of hearing loss but had normal hearing at $500-2000 \mathrm{~Hz}$ had at least mild impairment in the high frequencies.

$\S A$ presbycusis patient had normal hearing at speaking frequencies but had mild to moderate highfrequency impairment.

Table 6. Tympanometry results per ear, with number of cases that were bilateral

$\begin{array}{lrrr}\text { Type } & \text { Right* } & \text { Left* } & \text { Bilateral casest } \\ \text { A } & 192(51.9) & 185(50.0) & 169(45.4) \\ \text { Ad } & 9(2.4) & 17(4.6) & 0 \\ \text { As } & 15(4.1) & 8(2.2) & 0 \\ \text { B } & 146(39.5) & 151(40.8) & 109(29.3) \\ \text { C } & 8(2.2) & 9(2.4) & 2(0.5) \\ \text { Total } & 370 & 370 & 280(75.3)\end{array}$

*Some patients could not be tested, two for the right and two for the left ear. Percentages based on total per ear are indicated in parentheses.

tPercentages reported were based on total number of tests performed $(n=372)$.

Table 7. Otoacoustic emissions results per ear, with number of cases that were bilateral

\begin{tabular}{lccr|}
\hline Result & Right* $^{*}$ & Left* $^{*}$ & Bilateral casest \\
Pass & $63(37.5)$ & $57(33.9)$ & $52(31.0)$ \\
Refer & $105(62.5)$ & $111(66.1)$ & $100(59.5)$ \\
Total & 168 & 168 & $152(90.5)$ \\
*Percentages based on total per ear are indicated in parentheses. \\
TPercentages reported were based on total number of tests performed $(n=168)$.
\end{tabular}

\section{Auditory Brainstem Response}

Seven of 12 children who were tested with ABR had intact auditory pathways, while three children had profound hearing loss in at least one ear. There was concordance with OAE in four cases. Three adults were diagnosed with retrocochlear lesions; each was referred for different symptoms of dizziness, tinnitus and vertigo.

\section{DISCUSSION}

In this article, the annual statistics of the PNEl based on patient and audiologic records were comprehensively reviewed. The PNEI serves a mass-based population that extends over 16 of 17 country regions and a wide range of age groups from newborn to elderly which parallels the national demographic distribution. It also offers audiologic services to both charity and pay patients, and a majority block of working-age individuals that encompasses both the unemployed and workers across a variety of job strata, including laborers, workers in the trade, service and sales sectors, office and business personnel and professionals. Although majority of the patients' diseases were otologic, a wide spectrum of otorhinolaryngologic diseases, including rhinologic and oncologic entities, was studied in tandem with audiologic measurements. Therefore, it can be safely said that the PNEI is a major national referral center for audiology that holds much promise in providing not only direct services but also national surveillance of hearing status among different sectors of Philippine society.

Among the statistics that were available, the reasons for referral and pretest diagnoses when examined along with the results of different testing methods and also the different age groups may be useful to health providers. This gives rough estimates of prevalence rates for disease and audiologic states and establishes what kind of audiologic services must be provided to the population at large. Although it is well-known to Filipino otorhinolaryngologists that chronic otitis media is the most common otologic disease in practice that requires medical, surgical and audiologic interventions, it was shown that inner ear diseases comprise a major proportion of diseases as well. Common causes of sensorineural hearing loss (e.g. congenital, presbycusis), vertigo and tinnitus, with normal tympanometry, altogether accounted for at least 317 cases or $18.1 \%$ of referrals. In comparison, middle ear diseases, if taken together, represent at least $40.6 \%$. This may signal an increase in awareness of neurotologic disease among health practitioners, and at the same time a need to reassess current programs for possible expansion of subspecialty services.

One limitation of this study, however, is the large amount of missing data particularly for occupation, region of origin and pretest diagnosis. Also lag times from referral to testing was longest for $A B R$ and play pure tone, which may imply lack of patient resources and/or limitations in current capacity for PNEI, and may translate to increased dropout rates. It may then be required to reformat the current system of referral to PNEI and improve equipment and personnel availability to ensure better coverage of information. It is also notable that a very low percentage of referrals came from non-otorhinolaryngologic units. This may necessitate a campaign to other medical specialties on the 
ORIGINAL ARTICLES

indications for referral for audiology and the availability of such services at PNEI.

Newborn hearing screening, for example, should be championed among pediatricians and obstetricians to ensure a bigger population for OAE and ABR screening. From the "refer" rates in this study, it was obvious that hearing screening was very much limited to the highrisk child population. The prevalence for "refer" rates for one year of age or less was $71.3 \%$, much higher than previously reported. . $^{3-5}$ Even though a tertiary care population was described and, therefore, hearing impairment prevalence was expected to be high, if the pool for newborn hearing screening is not expanded, the prevalence estimate for congenital and early-life hearing impairment will remain high. At face value this may mean that the truly at-risk population is better targeted for service, but in reality it also means that a larger segment of the newborn to infant population is missed for hearing screening, which has great implications on speech and language development for those who are missed. ${ }^{6}$

Among the different age groups, school-age children formed the smallest group, with children aged 5-18 making up $13.1 \%$ of the total. Because the PNEl is open only during office hours, this low number may reflect conflict with school hours rather than hearing health. Extension and research activities for hearing screening among schoolchildren are therefore very much needed. Another target for outreach services are those provinces that are close enough to PNEl for patients to travel for testing and, therefore, for current lack of audiologic services within their community, patients from these provinces flock to PNEl. At the same time far-flung regions that are known not to have existing audiologic services should also be targeted for outreach hearing screening.

The elderly population, a traditionally underserved segment, comprised $13.4 \%$ of audiologic patients. As expected, presbycusis was diagnosed mostly within this age group, with $23.8 \%$ of those aged 60 and above having presbycusis. However it was shown in Table 3 that drops in threshold at high frequencies start to occur from about age 30. The contribution of noise and other disease states to this process is not known. It also remains to be seen whether high-frequency losses from aging should be considered "expected-for -age (and sex)" as is followed in current international standards, ${ }^{7}$ or whether such losses are definitely pathologic. Establishment of normative values for the Filipino population across age and sex would therefore likely impact current standards in national audiologic practice.

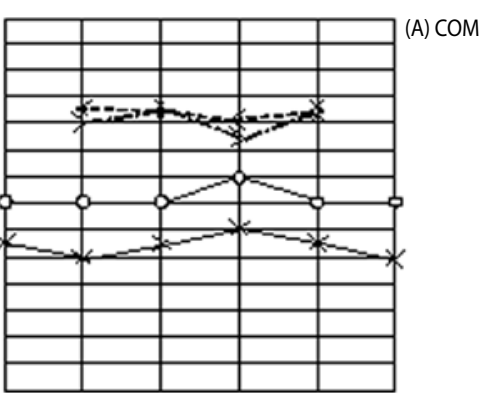

(B) Post-surgery
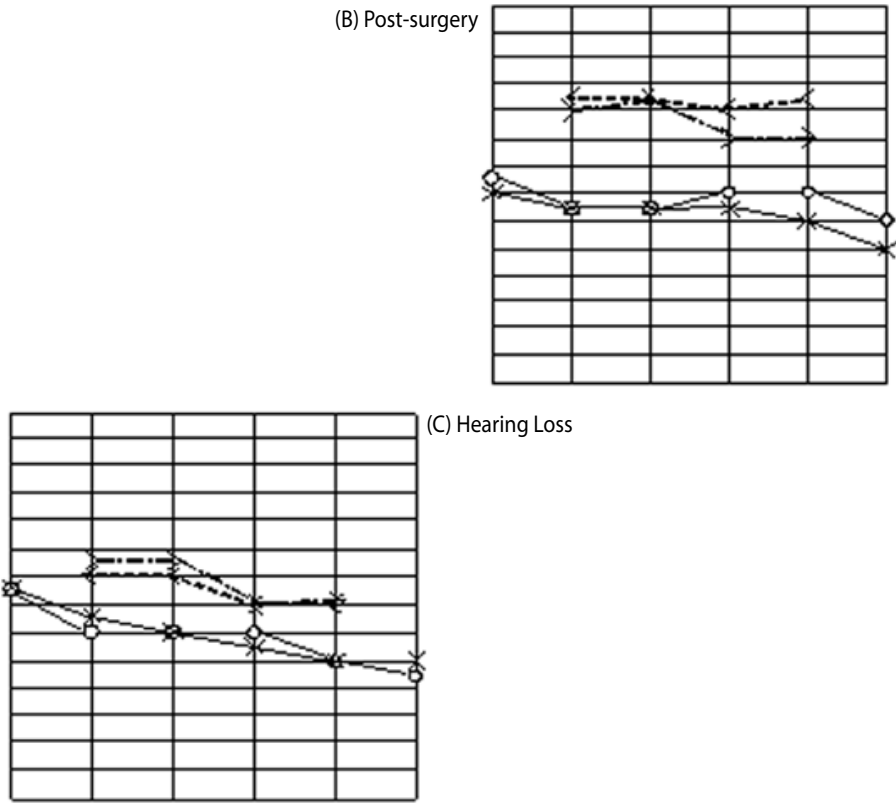

(C) Hearing Loss

(D) Tinnitus
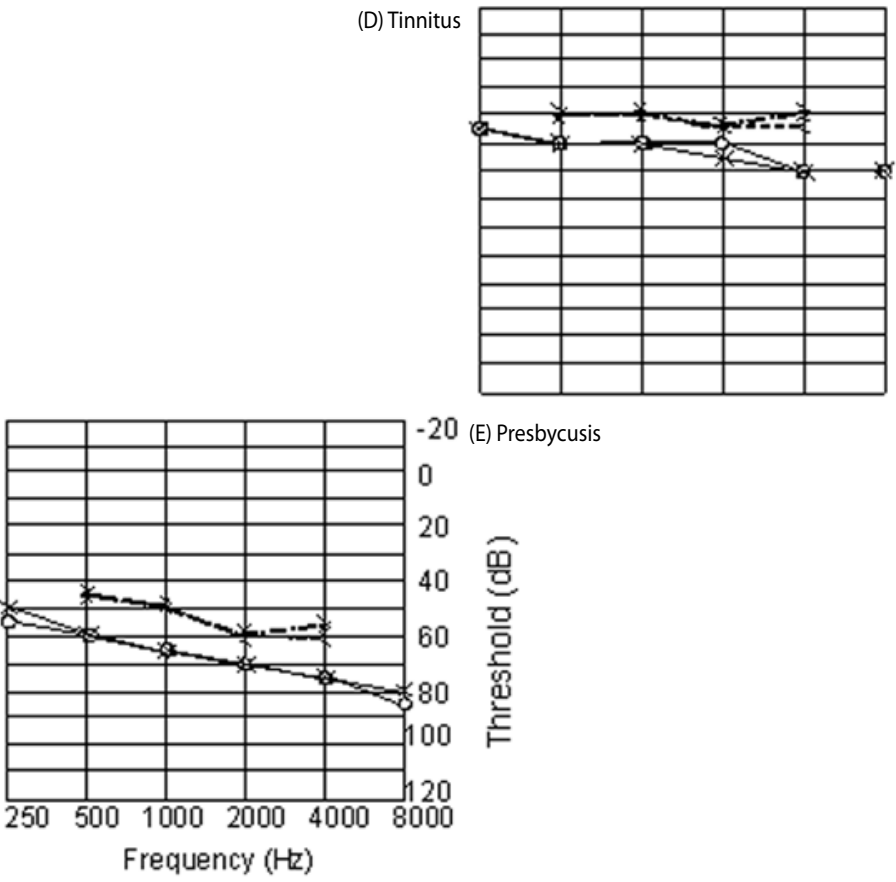

Figure 1. Sample audiograms for common diagnoses based on median hearing thresholds per frequency, including both air and bone conduction levels. Total numbers of patients per disease category are shown in Table 4, except for hearing loss ( $n=184)$. COM = chronic otitis media. Post surgical cases include patients who underwent mastoidectomy and/or tympanoplasty. 


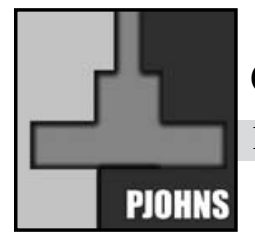

ORIGINAL ARTICLES

Philippine Journal Of Otolaryngology-Head And Neck Surgery

Vol. 22 Nos. 1 \& 2 JANUARY -JunE; JulY - DeCEMBER 2007

In conclusion, the PNEI, being located within the national tertiary care hospital, has high rates of prevalence for a wide variety of otologic diseases and audiologic abnormalities. To fulfill its basic objectives, the PNEI is looking forward to better preventive health care by planning to extend current services more towards hearing screening of a wider segment of the Filipino populace, including hearing surveillance across different age groups, country regions and labor sectors.

\section{ACKNOWLEDGEMENT:}

We are grateful to Melody Francisco and to Drs. Ma. Elaine Villanueva, Rowald Rey Malahito and Omar Carlo Sebastian for data encoding. We also thank the students of the Master of Clinical Audiology program and also Drs. Sebastian, Malahito and Villanueva for their invaluable help in testing the patients' hearing.

\section{REFERENCES:}

1. Yantis PA. Pure tone air-conduction threshold testing. In: Katz J, editor. Handbook of clinical audiology. 4th ed. Baltimore, MD: Williams \& Wilkins; 1994. p.107.

2. Republic of the Philippines Department of Labor and Employment [homepage on the Internet]. Manila: Department of Labor and Employment; c2005-2007 [cited 2007 March 16]. Available from: http://www.dole.gov.ph/.

3. Llanes EG, Chiong CM. Evoked otoacoustic emissions and auditory brainstem responses: concordance in hearing screening among high-risk children. Acta Otolaryngol. 2004 May; 124(4):387-90.

4. Quintos MR, Isleta PF, Chiong CC, Abes GT. Newborn hearing screening using the evoked otoacoustic emission: The Philippine General Hospital experience. Southeast Asian J Trop Med Public Health. 2003; 34 Suppl 3:231-3.

5. Chiong CM, Llanes EGD, Tirona-Remulla AN, Calaquian CM, Reyes-Quintos MR. Neonatal hearing screening in a neonatal intensive care unit using distortion- product otoacoustic emissions. Acta Otolaryngol. 2003 Jan; 123(2):215-8.

6. Yoshinaga-Itano C, Sedey AL, Coulter DK, Mehl AL. Language of early- and later-identified children with hearing loss. Pediatrics. 1998 Nov; 102(5):1161-71.

7. ISO 7029. Acoustics: Threshold of hearing by air conduction as a function of age and sex for otologically normal persons. Geneva: International Organization for Standardization; 1984. 